\title{
New Language Learning Environment: Employers' - Learners' Expectations and the Role of Teacher 4.0
}

\section{Tatiana Peredrienko}

South Ural State University, Russian Federation,peredrienkoti@susu.ru

\section{Oxana Belkina}

South Ural State University, Russian Federation, belkinaov@susu.ru

\section{Elena Yaroslavova}

Assoc. Prof., South Ural State University, Russian Federation, iaroslavovaen@susu.ru

$$
\text { | }
$$

The research attempts to reveal distinctive features of four basic patterns of the educational paradigm; aims at investigating the role of a teacher in a new languagelearning environment and finding a new approach to education for a "Teacher 4.0" to conform to technology-related changes in the society and, consequently, to employers' expectations. The data were collected and analysed via mixed research methods based on three stages, which allow revealing the needs of learners and employers, validating the learners' skills to be formed, determining the ways for demanded skills formation and outlining the role of a teacher in the new learning environment. The findings identify that the most demanded skills for new learners are digital literacy and critical thinking. The last one along with problem-solving are of great interest to employers as the most significant educational stakeholders. These skills make a core set sought after by a professional market. Based on received data, the functions of a teacher in the formation of these skills are stated and the educational environment for foreign language teaching is presented.

Keywords: language-learning environment, educational paradigm, core skills, teacher 4.0 , education 4.0

\section{INTRODUCTION}

Nowadays dynamic changes in the world and society have led to the vital necessity of educational paradigm transformation. Under the educational paradigm, we understand a set of key ideas that are recognized by the pedagogical community in a particular period of time. The paradigms succeed each other in the course of historical, economic and socio-cultural development of a society. The recent technological leap, which has had a drastic impact on lives and working conditions, is one of the main factors of the change

Citation: Peredrienko, T., Belkina, O., \& Yaroslavova, E. (2020). New Language Learning Environment: Employers' - Learners' Expectations and the Role of Teacher 4.0. International Journal of Instruction, 13(3), 105-118. https://doi.org/10.29333/iji.2020.1338a 
in the new century. In the modern world, we are surrounded by continuous computer innovations, various software tools in all areas of activity. The sphere of education should also keep up to date and not lag behind in the development. The expansion of digitalization requires new qualifications and skills both of a new learner and of a new teacher, which can be shaped only within a new approach to education.

The differences between educational paradigms are formed according to the following criteria: the goals set for the education system; ways to achieve the goals; understanding of the functions that the education system must perform in society; representation of the place of a teacher and a learner in the educational process; and nature of pedagogical interactions (Popov et al., 2012).

The paradigm shift from Education 1.0 to Education 4.0 represents a response to society's expectations related to emergence of technology-driven innovations and social phenomena that radically alter the nature of instruction; reflects the evolution of needs and requirements of both learners and teachers; reveals a necessity for acquiring new competencies sought after by employers; ascribing new roles to the teacher (Chang et al. 2015).

Technology-based teaching accords full facilities for self-learning opportunity at student's own pace (Hariharasudan \& Kot, 2018). Learners start being actively involved into customizing, improving and perfecting the educational process. They turn from passive consumers of higher education to partners by seeking for relevant information through diverse available resources, asking the teacher for additional information and support that satisfy their immediate needs and specific interests. Thus, the center of the educational process is not just the knowledge imparted to students, but also their active acquisition in the process of cognitive and research activities at universities.

However, this does not mean that the importance of a teacher is reduced, it is being transformed. The teacher becomes a navigator in the world of information. He assists in choosing the most reliable sources, helps to distinguish valuable information and turn it into the student's knowledge. Therefore, modern education is a collaboration of a teacher and a learner.

\section{CONTEXT AND REVIEW OF LITERATURE}

The necessity of the educational paradigm transformation and the need for responding to new demands of a digital learner in the innovative environment were discussed by many scholars (Ursul \& Ursul, 2012; Turchen, 2012; Puncreobutr, 2016; Millán \& Núria Valls, 2014, etc).

As the educational tasks are becoming more complex and the challenges are diverse, a new concept of teaching to conform to technology-related changes should also be considered. Likewise, the ability of teachers to go through the digital era in the process of education and their willingness to adapt to the changing educational environment are important issues for discussion. A. Abdelrazeq, D. Janssen and other (2016) assume that a new concept of teaching and being a teacher is to be scrutinized. This concept is referred to as "Teacher 4.0". 
The idea of a new educator (Teacher 4.0) is connected with Education 4.0 that stems from a gradual evolution of educational technologies. Harkins (2008) named the education in the era responding to the agrarian society as Education 1.0, industrial society as Education 2.0, globalized technology as Education 3.0, innovation as Education 4.0.

The conception of Education 4.0 is the feedback to the requirements of Digital Industry 4.0 for new specialists. Dr.Vichian Puncreobutr (2016) notes that Education 4.0 is catering to the need of society in the "innovative era". This learning management supports the learner's ability to apply the new technology, which will help them to develop according to the changes in society.

Scientists studied the concept of Education 4.0 and identified the following characteristics. According to Peter Fisk (2017), there are nine of them:

- it can be taken place anytime anywhere;

- it is based on students' individual needs;

- it is flexible in delivery to students;

- it motivates students to more project-based learning;

- it is practice oriented;

- it motivates students to data interpretation using their theoretical knowledge;

- it allows to assess students differently;

- it takes into account students' opinion and let them be more independent in their own learning;

- it shifts the major learning responsibilities from a teacher to a student.

So, Education 4.0 can be characterized as accessible (giving possibilities of autonomous learning), individual, flexible, practical and project-based learning oriented; motivating to interpretation and independence, having variable assess.

The main goal of Education 4.0 is the improvement of digital competencies and skills of learners across all levels, and the increase of digital technologies usage for learning, teaching and assessing. The everyday use of digital gadgets is becoming a part of our lives; consequently, IT devices are to be integrated into education and become its key component. Knowing how technology works can help learners be ready to Education 4.0. That is why teachers must consider the process of digital media curriculum as a learning model.

In general, digital competencies encompass the knowledge and skills required for an individual to be able to use information and communications technology to accomplish goals in personal or professional life. But digital competencies should be associated not only with technical skills, but more focused on cognitive, social and emotional aspects of working and living in a digital environment (Building Digital Competencies to Benefit from Frontier Technologies, 2019).

To meet the requirements of Education 4.0, modern smart universities face the necessity to create multi-purpose, highly stimulating digital environment for learning. The 
University in the South Ural has launched diverse educational projects among which Dynamic Learning Language Environment is of ultimate significance to shift from Education 3.0 to 4.0 due to internationalization of education and university involvement into global research).

\section{METHOD}

This study aims at investigating the role of a teacher in a new language-learning environment and finding a new approach to education for a "Teacher 4.0" to conform to technology-related changes in the society and, consequently, to employers' expectations. To achieve this, we are going:

- to study different educational patterns in comparison,

- to reveal the needs of a new learner and an employer,

- to validate the skills to be formed,

- to determine the ways for demanded skills forming,

- to outline the role of a teacher in the educational process,

- to offer a new learning environment.

For solving the following tasks the mixed methods research is used. This methodology requires a purposeful mixing of methods in data collection, data analysis, and interpretation (Shorten \& Smith, 2017).

At the first stage of the research for better understanding of the challenges and the requirements for Education 4.0, the formats of Education 1.0, 2.0, 3.0 and 4.0 are studied in comparison. This lets authors identify how the skills have been changing over the development of educational paradigm.

At the second stage the needs of a new learner and an employer are revealed with the help of the survey that is conducted among 45 Bachelor students and 45 employers selected randomly. They are offered a Likert scale survey including 6 positions that represent the skills, which are in the highest demand in the era of Education 4.0 compiled based on the analysis of the scientific literature related to the subject. This lets authors identify and validate the skills to be formed.

At the last stage through the analysis of the demanded skills a new approach to education for a "Teacher 4.0" is offered in order to conform to technology-related changes in the society.

\section{Instruments and Data Collection}

Two questionnaires for students and employers submitted through Google application and semi-structured interviews were used for data collection. The questionnaires were designed for identifying and validation of the most demanded skills for 45 learners (fulltime second year students where "English as a Foreign Language" is a compulsory course) and 45 employers (the heads of large and small-scale enterprises that collaborate with the University on a regular basis).

Learners deal with a particular aspect every single term. The third semester centres on English for Academic Purposes (EAP), whereas the fourth term is for English for 
Specific Purposes (ESP). Consequently, the target audience for the research are the students who have already acquired some academic skills and gained particular experience via project-based activity related to professional area. The Likert scale was used to measure their opinions and attitudes. To verify the quantitative data, the interview was administered to 10 randomly selected new learners and employers.

\section{FINDINGS}

\section{Conceptual Overview of Educational Patterns}

It is customary to distinguish between the next four patterns of education with regard to corresponding four WEB platforms (Harkins, 2008; Puncreobutr, 2016; Abdelrazeq et al., 2016; Gerstein, 2014).

Education 1.0 is a standard one-size-fits-all education, where teachers are regarded as gatekeepers of information, a type of "sage on the stage" while learners are primarily referred to as mere recipients of pre-packaged set of knowledge who follow the instructions of their mentors.

Education 2.0 is based on three Cs method - communicating, contributing, and collaborating, the transition away from top-down, strict hierarchical control of conventional teaching. Learners tend to move from just obtaining information to being able to manage content through collaboration via social networks. Nevertheless, with Education 2.0 a teacher is still a chief conductor who orchestrates the process of learning.

Education 3.0 is also about the three Cs but in a totally different set - connecting, creating, and constructing. This educational pattern aims at supplying learners with customized relevant, interactive and networked content, based on individual interests (Gerstein, 2014). The core idea here is to create knowledge by supporting self-learning. The instructor radically changes his educational role acting as the "guide on the side". Thus, Education 3 can be defined as self-tailored, interest-based learning where problem solving, innovation, and creativity fuel education and students are to generate knowledge, not merely to consume information.

Education 4.0 is geared towards the needs of the society in the age of innovation. The university is not considered merely as a "school" anymore; it refers rather to a "smart factory" or even an "educational hub" involving various stakeholders within their community, providing the most appropriate resources for combination of teaching, learning, researching and knowledge exchange with partners and collaborators from inside and outside education.

Creativity and willingness for innovative activity become the cornerstone of WEB 4.0 and consequently, Education 4.0. It involves utilizing the "Internet of Things" to prepare learners for whatever they may encounter at the workplace.

Therefore, business-based innovative digitalization agenda almost in all spheres of life specifies enormous shift in educational sector towards development of more "down-toearth", applied skills, competences and qualities that are in great demand in a highly competitive environment. Innovative skills (other experts refer to them as soft or life skills) become extremely significant for learners to further fit in ever-changing cyber 
society, to be able to get adapted to modifying working conditions, to be professionally required by labour market. Such skills train the learner for responding to challenges that arise in professional environment, for evolving from being a survivor to an achiever.

\section{Evolution of Skills in the Course of Education Format Development: From Education 1.0 to Education 4.0}

There exist different typologies of skills and competencies necessary for a learner to succeed in life and profession. The most reputable of such classifications is the Cambridge Framework of Life Competencies / Skills. The Cambridge experts scoured all available resources to identify forty-two key life competencies / skills embracing seven core areas: creativity, critical thinking and problem solving, digital literacy, learning to learn, communication, collaboration, emotional development and social responsibilities (The Cambridge Framework for Life Competencies, 2016).

The authors arrived at the decision to focus on several most significant elements from the above-mentioned six areas to constitute the portfolio of pivotal skills for a modern digital learner of a smart university, and to see how these skills have been changing over the development of educational paradigm. The data are presented in Table 1.

Table 1

Development of skills via transformation of educational patterns Digital literacy

Education Almost lack of prior IT experience and digital skills. Experts mainly refer to this period as pure digital

1.0 consumerism, when the users merely obtain information from different, sometimes not so much relevant resources. Simple operations for handling information: mainly e-mail and Internet sites.

Education Use of social networks and educational platforms such as Twitter, Facebook, Edmodo, Schoology to

2.0 communicate and share ideas with other co-learners and instructors. Experts tend to refer to this stage as advanced digital consumerism with development of digital competencies to properly locate, evaluate, and use efficiently the data required.

Education Extensive use of advanced social network capacities for in-depth research, modelling and simulating

3.0 professionally related cases and projects. Electronic management of any results obtained. Emergence of digital applications for educational purposes.

Education The learners represent the first generation of digital natives, having grown up using technology since birth.

4.0 Exceptional ability to work in diverse virtual educational environment. A confident use of e-learning technologies. All result records and monitoring are maintained in a digital form. Extensive use of cloud technologies and mobile applications for learning. Sustainable development of learning management systems, digital educational online platforms, massive open online courses (MOOCs), online support for any curricula developed. Critical thinking

Education Rote memorization, drilling, basic test-taking skills are the most habitual ways of learning which reflect the limitations of deductive education. Learners merely absorb information and process it according to the strict teacher's instructions.

\begin{tabular}{ll}
$\begin{array}{l}\text { Education } \\
1.0\end{array}$ & $\begin{array}{l}\text { Rote memorization, drilling, basic test-taking skills are the most habitual ways of learning which reflect the } \\
\text { limitations of deductive education. Learners merely absorb information and process it according to the strict } \\
\text { teacher's instructions. }\end{array}$ \\
\hline $\begin{array}{l}\text { Education } \\
2.0\end{array}$ & $\begin{array}{l}\text { Elements of critical thinking are introduced into the standardized educational mix, alongside absorbing } \\
\text { information from the sources indicated, learners are additionally expected to synthesize, analyze, order and } \\
\text { compare data. }\end{array}$ \\
\hline $\begin{array}{l}\text { Education } \\
3.0\end{array}$ & $\begin{array}{l}\text { Apart from traditional set of skills aimed at processing and applying data, learners arrive at independent } \\
\text { conclusions supported by the information learned and teacher's instructions made. Citation is perceived as a tool } \\
\text { to enhance own opinion by means of researched facts or other published information. }\end{array}$ \\
\hline $\begin{array}{l}\text { Education } \\
4.0\end{array}$ & $\begin{array}{l}\text { A developed skill for reflective analysis, profound ability to raise vital issues, by formulating them clearly and } \\
\text { precisely; gathering and assessing relevant information, arriving at well-reasoned conclusions and solutions, } \\
\text { examining them based on appropriate criteria and standards; the ability to judge open- mindedly within alternative } \\
\text { concepts. }\end{array}$ \\
\hline \begin{tabular}{l} 
Creativity \\
\hline Education
\end{tabular} & $\begin{array}{l}\text { Prevalence of the one-answer approach, the traditional way of supplying learners with selected facts, formulas, } \\
\text { and theories to help them memorize and come up with expected answers. }\end{array}$ \\
\hline Education & Stimulating educational environment, namely digital platforms and social media fuel creative thinking, which \\
\hline
\end{tabular}




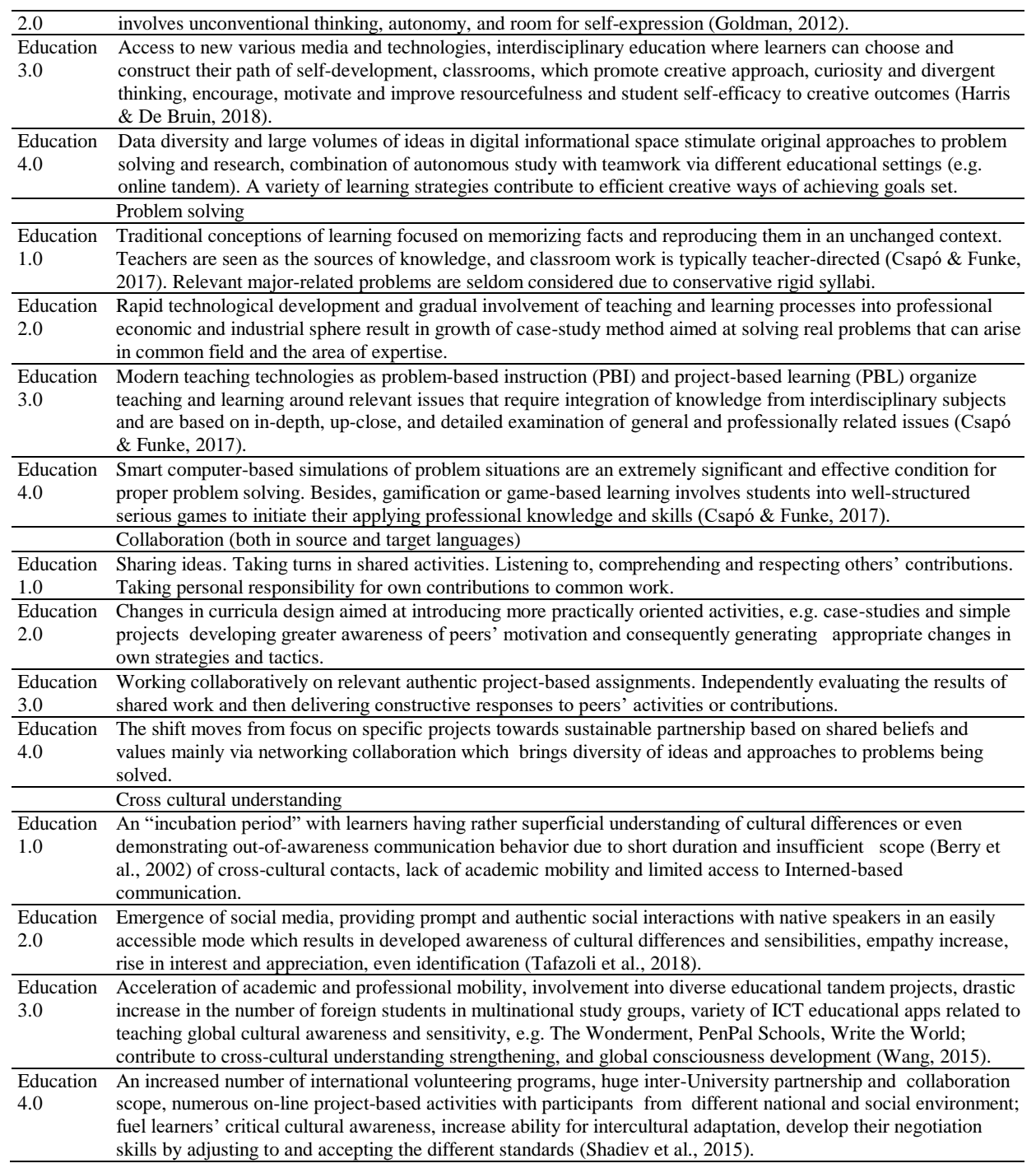

\section{Likert Scale Survey and Questionnaires}

An overview of the skills transformation over the education evolution is vital for further research as it contributes to understanding what is to be expected in the sphere of teaching, how to manage changes, how to improve skills that help a learner to be personally and professionally competent, efficient and competitive. The survey based on Likert scale helps to reveal expectations of both learners and employers, identify if there exist any gaps in priorities of both parties, and develop the strategy for the teachers how to manage this challenge and assist in further learning. 
The next task was to study the attitudes of respondents and to identify the importance of the above-mentioned skills for learners and their potential employers. The questionnaires were developed in the Google application in which they were invited to evaluate the skills on the Likert scale and to explain their choice.

Likert scale was chosen for the analysis as it helped to measure opinions and attitudes more precisely. The respondents didn't choose between "important/unimportant", instead they rather expressed the importance of the skills which were in the highest demand for Education 4.0 with the help of the quality descriptive words: very important, important, fair, unimportant, unwanted.

\section{Skills and competences}

\section{Rate the following akills on a soald.} Very important - 5, important - 4, Fair = 3, Unimportant - 2, Unwanted -

1. Digital literaoy (a set of knowledge and skills that are necessary for the safe and effective use of digital technologies and internet resources)

01

$0=$

$\mathrm{C}^{3}$

04

$\mathrm{O} s$

Figure 1

Likert Scale in the Questionnaire

The questionnaires were given to 45 new learners and 45 employers who should rate the offered skills according to the importance for them and explain why. Before the questionnaires the data about the respondents were analysed to ensure the group equivalency.

The carried-out survey among the employers and new learners allowed to define the most demanded skills and competences for them and helped to validate their importance for interviewed. The results of the data collected through the questionnaire of new learners are presented in Table 2.

Table 2

Likert Scale Survey (Learners)

\begin{tabular}{llllll}
\hline Skills & Very Important & Important & Fair & Unimportant & Unwanted \\
\hline Digital literacy & $73.4 \%$ & $22.2 \%$ & $2.2 \%$ & $2.2 \%$ & $0 \%$ \\
\hline Critical thinking & $64.4 \%$ & $26.7 \%$ & $6.7 \%$ & $2.2 \%$ & $0 \%$ \\
\hline Creativity & $44.4 \%$ & $24.5 \%$ & $26.7 \%$ & $4.4 \%$ & $0 \%$ \\
\hline Problem solving & $64.4 \%$ & $31.2 \%$ & $4.4 \%$ & $0 \%$ & $0 \%$ \\
\hline $\begin{array}{l}\text { Collaboration (both in source } \\
\text { and target languages) }\end{array}$ & $40 \%$ & $33.4 \%$ & $24.4 \%$ & $2.2 \%$ & $0 \%$ \\
\hline \begin{tabular}{l} 
Cross cultural understanding \\
\hline
\end{tabular} & $31.2 \%$ & $37.6 \%$ & $24.4 \%$ & $6.7 \%$ & $0 \%$ \\
\hline
\end{tabular}

The new learners understand the importance of the defined skills and competences for their future career. All of the skills got more than $69 \%$ for their importance or great importance. The most valued skill for learners is Digital literacy (for $73.4 \%$ very important and $22.2 \%$ important). But the least demanded skills are Creativity (for $44 \%$ 
very important and $24.5 \%$ important) and Cross cultural understanding $(31.1 \%$ and $37.8 \%$ ). The last skill also gets $6.7 \%$ for unimportance but this can be explained by the students' current orientation towards the domestic market. If learners can't see the application of a skill, they won't see the value of it. It is interesting to notice that none of the students marked the defined skills as unwanted. That together with the high per cent $(69 \%)$ for importance and great importance proved the significance of the defined skills for new learners.

If we consider the explanations of the demanded skill choice, then it can be noted that the most frequent answers were: "without this skills it is impossible to live and work in the modern world", "without this skill it is difficult to navigate in the modern world", "you cannot do without this skill in the new century" and "this skill brings greater work efficiency in our time". So, the choice of the demanded skill is explained by the inability to exist in the modern world and work more efficiently.

The data gathered through the questionnaire of the employers are processed and introduces in Table 3.

Table 3

Likert Scale Survey (Employers)

\begin{tabular}{llllll}
\hline Skills & Very Important & Important & Fair & Unimportant & Unwanted \\
\hline Digital literacy & $64.4 \%$ & $31.2 \%$ & $2.2 \%$ & $2.2 \%$ & $0 \%$ \\
\hline Critical thinking & $77.2 \%$ & $20.6 \%$ & $2.2 \%$ & $0 \%$ & $0 \%$ \\
\hline Creativity & $31.2 \%$ & $31.2 \%$ & $31.2 \%$ & $6.4 \%$ & $0 \%$ \\
\hline Problem solving & $95.6 \%$ & $4.4 \%$ & $0 \%$ & $0 \%$ & $0 \%$ \\
\hline $\begin{array}{l}\text { Collaboration (both in source and } \\
\text { target languages) }\end{array}$ & $73.4 \%$ & $22.2 \%$ & $2.2 \%$ & $2.2 \%$ & $0 \%$ \\
\hline Cross cultural understanding & $26.7 \%$ & $24.5 \%$ & $44.4 \%$ & $2.2 \%$ & $2.2 \%$ \\
\hline
\end{tabular}

The employers stated the greatest importance of Critical thinking (77.2\% very important and $20.6 \%$ important) and Problem solving (95.6\% and $4.4 \%)$ skills. The need of Digital literacy $(64.4 \%$ and $31.2 \%)$ and Collaboration (both in source and target languages) were recognized as wanted by most of the employers too. However the preference to Creativity (31.2\% very important and $31.2 \%$ important) and Cross cultural understanding $(26.7 \%$ and $24.5 \%)$ was lower. The results of the research represented the indifferent attitude to these skills (31.2\% and $44.4 \%$ respectively). The Cross cultural understanding was considered unimportant $(2.2 \%)$ and even unwanted $(2.2 \%)$. It may be connected with greater market orientation and separation of functions in the company.

The main difference between the questionnaires for learners and employers was the question: Add the skills that are necessary in your area. The respondents suggested the following answers: teamwork skill, effective communication skill and multitasking skill. These skills are very necessary in the modern world too, but their formation has much in common with the formation of such skills as collaboration (both in source and target languages) and problem solving.

In order to verify the quantitative data the interview was administered to 10 randomly selected new learners and employers. The respondents were asked to rank the offered 
skills in order of the importance, the results were also processed. The data obtained are presented in Figures 2 and 3.

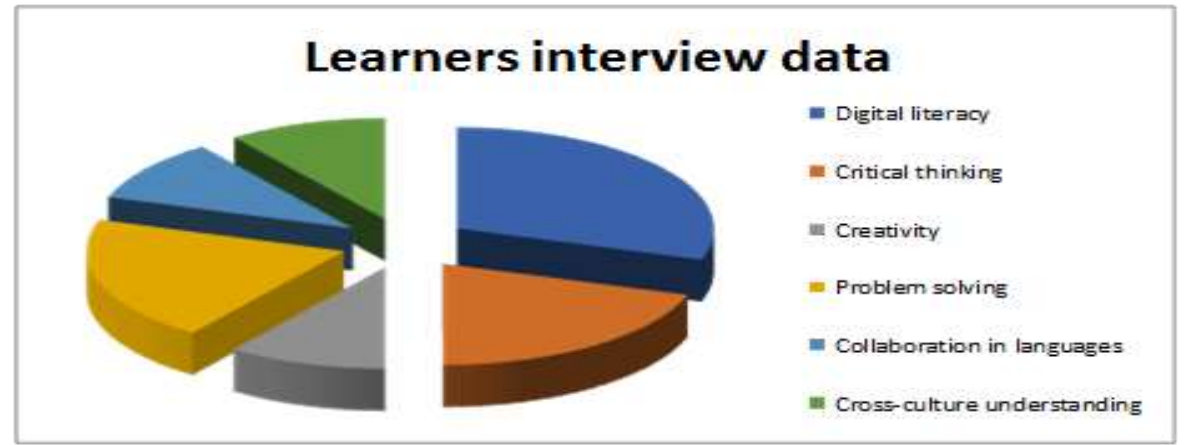

Figure 2

Learners Interview Data

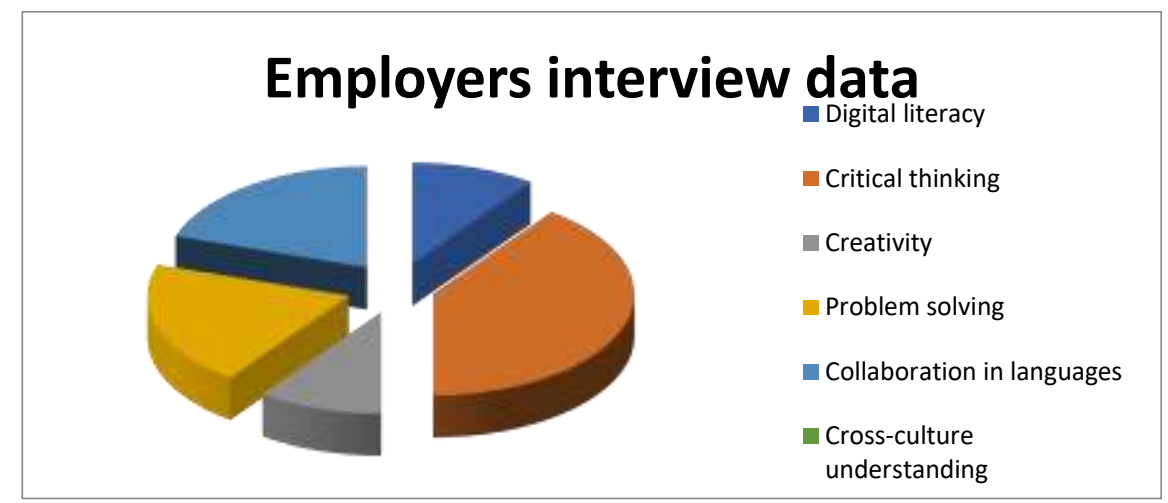

Figure 3

Employers' Interview Data

The most demanded skills for learners are digital literacy, critical thinking and problem solving. The requirements of employers are different they put critical thinking in the first place but they are also interested in problem-solving and collaboration in languages. So, data gathered through the interview have much in common with data of questionnaire and this verify the quantitative data.

\section{The Role of a Teacher in the Dynamic Language Learning Environment}

The rate of change in education is incredibly fast, whereas the level of predictability of what is yet to come is extremely low and these trends are accelerating. In plain terms, the teacher's professional excellence and his responsibility for what he transmits to a learner today might well be irrelevant or even wrong in the nearest future. Consequently, a teacher must keep pace with at least basic innovations and advances in the world in general, in his professional sphere, and in the areas that are of particular interest for his learners' target audience and to their potential employers. 
To find the most appropriate form of instruction in the new learning environment, teachers now have to combine conventional teaching "face-to-face" in the classroom with the use of blended environments outside the classroom via different digital platforms and resources. Besides, to guide and support students on an individual basis, provide them with scaffolding to further differentiate and personalize their learning path is an extremely important part of the teacher's activity. As many educational opportunities and resources constantly emerge, a teacher is to be informed about them, be able to navigate them, offer the most useful ones to his learners and further monitor their work and progress. Besides, a proficient teacher is supposed to design his tailored electronic courses, be it just a Moodle course or even a MOOC. And all this must be done taking into account the needs and requirements of potential employers, otherwise teaching becomes useless and irrelevant and turns into TENOR - Teaching English for No Obvious Reason. Essentially, teaching is becoming multi-dimensional.

\section{DISCUSSION}

To respond to challenges of Education 4 requirements (in terms of learner-centered activity, digitalization, inductive type of instruction, project-based learning pattern, focus on acquiring life competences / soft skills, emphasis on university-industrial sector collaboration), Russia is implementing an ambitious government-run project 5-100 which takes into account the most efficient practices and initiatives taken by best world universities in the sphere of tertiary education. The ultimate goal of Project 5-100 is to maximize the competitive position of a group of leading Russian universities in the global research and education market; its intermediate objectives include making education more effective, preparing a learner for long-life learning, providing every condition to acquire relevant knowledge and skills supported by real projects and internships organized by industry and business.

Regarding the issues researched, learners reported to need badly the above mentioned skills and competences, sought-after by employers in new Society 4. Students who are proficient in these soft skills tend to be effective in their job searches and interviews and thus are more likely to be hired by more demanding employers. They make every effort to be productive, retained and promoted on the job, and in the long run they tend to earn more than those who lack those skills. Such employees are expected to contribute to the collective efficiency, productivity, and progress of the enterprise, and, consequently, when it is time to start their own business, they are more likely to reach success.

To shape and develop such skills a new educational environment is required which presupposes implementation of new formats of work, types of learning activities, and approaches to teaching.

To illustrate how the role of a teacher in the learning language environment is organized nowadays, let us refer to the case of South Ural State University (national research university), Chelyabinsk, Russia, a participant of 5-100.

Within the 5-100 Project framework, SUSU collaborates with Cambridge University and has direct access to its learning management system via which learners study course content, perform tasks in the online workbook, watch video materials, do listening tasks, 
take tests, post their reviews, participate in games. Besides, they can come up with their ideas and discuss some vital issues via blogs and forums; create and post lists, essays, and stories via wiki and portfolio. All these tasks are submitted in such a way as to form all the demanded skills.

Moreover, the majority of SUSU foreign language teachers design and set up their tailored courses for particular majors (bachelor's, master's and postgraduate degrees) based on the university corporate learning management system Moodle. These courses usually involve interconnected modules of such aspects as pronunciation, vocabulary, grammar, reading, listening, writing and functional language.

Besides, students are recommended to join online courses placed in the University Moodle system that are elaborated by native speakers who signed a contract with the University for real-time one-to-one online English immersion learning. Right now, the course on soft skills elaborated by Norbert Berger, a professor from Graz University, is in great demand.

Likewise, students are suggested to participate in tandem online projects, organized via networks, namely Facebook with foreign Universities. For instance, not a long time ago we finalized the project between SUSU and the University of North Carolina Wilmington aimed at mutual language training between Russian and American students.

Also, the most motivated students are encouraged to join Coursera MOOCs or any other ones, to develop their professional skills. If they enroll in a course, then they have to report on their progress in the form of regular Ted Talk presentations in the group.

As SUSU establishes its position as SMART, innovative University of digital transformation, project education plays an increasingly pivotal role. Learners take part in individual or team projects, organized by the degree-granting departments along with potential employers. This type of student activity is integrated into Foreign Language curricula and syllabi, consequently, students should report on their progress as well in the class.

A regular and final assessment is organized online too, which makes the process transparent and understandable.

All these tools, methods and technologies help teachers to easily manage classes and track their students' progress, highlighting strengths and weakness areas for ongoing performance improvement and demanded skills formation.

The new educational environment in the study of foreign languages is formed as a result of the informatization of society and teachers' response to these changes. And it is very important to follow the development and continue studying the didactic potential of the information and communication environment as a technological basis and an integral component of the modern training system.

\section{CONCLUSION}

The fourth industrial revolution is substantially altering our reality. The phenomena and technologies like artificial intelligence (AI), augmented reality (AR), big data and the 
internet of things are sure to have an enormous impact on all jobs and industries, let alone education as change-sensitive and responsive to the needs and demands of society.

The two crucial elements that affect education right now are access to information, and the rate of change. Learners nowadays consider digital sources of information, including networks, mobile computing devices, and various applications as a primary link to the data required. Such accessibility is a tool of creation and dissemination of knowledge that some experts refer to as cognitosphere (Lichtman, 2017). Thus, a teacher, above all, must be digitally competent, which implies he should be open to trying and properly applying new digital and virtual stuff, and be well aware of what is happening in cognitosphere, what resources are the most sought-after among his learners, what educational and training tools have already emerged or are just about to do it.

The study presents the data that provide a better understanding of learners' and employers' needs. Specifically, this study describes the language learning environment aiming to form the demanded skills. Universities now play an important role in determining and training soft skills among the students. The mentioned skills are very vital to enable learners to venture into the job market after graduating from the university. The results received are also extremely useful for understanding the Role of a Teacher in the educational process. Without understanding the Learners' - Employers' expectations and without the complete analysis of the requirements, it is impossible to define the objectives and tasks of a new Teacher. The further research can be conducted on the curriculum for soft skills development based on the received data.

\section{REFERENCES}

Abdelrazeq, A., Janssen, D., Tummel, C., Richert, A., \& Jeschke, S. (2016). Teacher 4.0: requirements of the teacher of the future in context of the fourth industrial revolution. ICERI2016: 9th International Conference of Education, Research and Innovation: Conference Proceedings, 8221 - 8226.

Berry, J. W., Poortinga, Y. H., Segall, M. H., Dasen, P. R. (2002). Cross-cultural psychology: Research and applications. New York, NY: Cambridge University Press.

Building Digital Competencies to Benefit from Frontier Technologies. (2019). United nations conference on trade and development (UNCTAD). New York: United Nations Publications.

The Cambridge Framework for Life Competencies. (2016). Cambridge University Press.

Chang, Hsin-Yi, Chia-Yu Wang, Min-Hsien Lee, Hsin-Kai Wu, Jyh-Chong Liang, Silvi W. Y. Lee, Guo-Li Chiou, Hao-Chang Lo, Jing-Wen Lin, Chung-Yuan Hsu, and et al. (2015). A review of features of technology-supported learning environments based on participants' perceptions. Computers in Human Behavior, 53, 223-37.

Csapó B., \& Funke J. (2017). The development and assessment of problem solving in 21 st-century schools. The Nature of Problem Solving. Using Research to Inspire 21st Century Learning. 19-32. 
Fisk, P. (2017). Education 4.0...the future of learning will be dramatically different, in school and throughout life. Retrieved from https://www.thegeniusworks.com/2017/01/future-education-young-everyone-taughttogether.

Gerstein, J. (2014). Moving from Education 1.0 through Education 2.0 towards Education 3.0. In L. M. Blaschke, C. Mr Kenyon, \& S. Dr Hase (Eds.), Experiences in self-determined learning (pp.83-98). CreateSpace Independent Publishing.

Goldman, S. (2012) Adolescent Literacy: Learning and Understanding Content. The Future of Children, 22(2), 89-116.

Hariharasudhan, A., \& Kot, S. (2018). A scoping review on digital English and education 4.0 for industry 4.0. Social Sciences, 7(11), 1-13.

Harkins, A. (2008). Leapfrog principles and practices: Core Components of Education 3.0 and 4.0. Futures Research Quarterly draft, 24(1), 19-31.

Harris, A., \& De Bruin, L. (2018). Creativity in education. Oxford Research Encyclopedia of Education. 1-29.

Lichtman, G. (2017) \#EdJourney: A roadmap to the future of education. Jossey-Bass.

Millán, C., \& Núria Valls, M. (2014). The paradigm shift in education that involves the information society and ITC (Information Technology and Communication). International Journal of Humanities and Social Science, 4(14), 207 - 212.

Popov, V. V., Bashmakov, A. I., \& Kruglov, Yu. G. (2012). Creative pedagogy: Methodology, theory, practice. Moscow: Binom.

Puncreobutr, V. (2016). Education 4.0: New challenge of learning. St. Theresa Journal of Humanities and Social Sciences, 2(2), 92 - 97.

Shadiev, R., Hwang, W., \& Huang, Y. (2015) A pilot study: Facilitating cross-cultural understanding with project-based collaborative learning in an online environment. Australian Journal of Educational Technologies, 31(2), 123-139.

Shorten, A., \& Smith, J. (2017). Mixed methods research: expanding the evidence base. Evidence-based nursing, 20(3), 74-75.

Tafazoli, D., Gomez Parra, M. E., \& Huertas-Abril, C. A. (2018). Cross-cultural perspectives on technology-enhanced language learning. IGI Global.

Turchen, D. N. (2012) The change of educational paradigm in the 20th and at the beginning of the 21 st centuries. Historical and socially educational thought, 4, 118-121.

Ursul, A. D., \& Ursul, T. A. (2012). Evolutionary paradigms and education models of the XXI century. Modern Education, 1, 1-67.

Wang, L. (2015) Study on cross-cultural communication competence construction in English teaching. Proceedings of the 2015 International Conference on Education Technology and Economic Management. 351-358. 